\title{
Erratum to: The clinical and genetic characteristics in children with mitochondrial disease in China
}

\author{
Fang Fang ${ }^{1}$, Zhimei Liu ${ }^{1}$, Hezhi Fang ${ }^{2}$, Jian $\mathrm{Wu}^{3}$, Danmin Shen ${ }^{1}$, Suzhen Sun ${ }^{4}$, Changhong \\ Ding $^{1}$, Tongli Han ${ }^{1}$, Yun $\mathrm{Wu}^{1}$, Junlan $\mathrm{Lv}^{1}$, Lei Yang ${ }^{1}$, Shufang Li ${ }^{1}$, Jianxin $\mathrm{Lv}^{2}$ \& Ying Shen ${ }^{1 *}$ \\ ${ }^{1}$ Department of Neurology, Beijing Children's Hospital, Capital Medical University, National Center for Children's Health, Beijing 100045, \\ China; \\ ${ }^{2}$ Inspection Medical School, Wenzhou Medical College, Wenzhou 325035, China; \\ ${ }^{3}$ Translational Medical Center, The General Hospital of the Chinese People's Liberation Army, Beijing 100853, China; \\ ${ }^{4}$ Department of Neurology, Children's Hospital of Hebei Province, Hebei Medical University, Shijiazhuang 050030, China
}

Erratum to: SCIENCE CHINA Life Sciences, July 2017, Vol.60 No.7: 746-757 doi: 10.1007/s11427-017-9080-y

1. The post code for the fourth address in the affiliation should be 050031 .

2. Three items are missing in the first row of Table 1. The correct form of the first row is as follows:

\begin{tabular}{|c|c|c|c|c|c|c|c|c|c|}
\hline \multirow{2}{*}{ ID/Sex } & \multirow{2}{*}{$\begin{array}{c}\text { Age of onset } \\
\text { (Year) }\end{array}$} & \multirow{2}{*}{ Clinical presentation } & \multicolumn{2}{|c|}{ Lactate $\left(\mathrm{mmol} \mathrm{L}^{-1}\right)$} & \multirow{2}{*}{ Brain MRI/CT } & \multirow{2}{*}{$\begin{array}{l}\text { Family } \\
\text { history }\end{array}$} & \multirow{2}{*}{ Phenotype } & \multirow{2}{*}{ Gene } & \multirow{2}{*}{ Mutation and ratio } \\
\hline & & & Blood & CSF & & & & & \\
\hline $1 / \mathrm{F}$ & 1 & $\begin{array}{l}\text { MR, regression, gastrointestinal } \\
\text { symptoms, weakness, seizure, } \\
\text { recurrent encephalopathy, short } \\
\text { stature, hirsutism, weight loss }\end{array}$ & 5 & NA & brain atrophy & + & MELAS & $M T-T L 1$ & A3243G 69.2\% \\
\hline
\end{tabular}

3. The second "55\%" in the fourth paragraph of DISCUSSION should be $50 \%$.

4. "MLEAS" in the sixth paragraph of DISCUSSION should be MELAS.

The online version of the original article can be found at http://dx.doi.org/10.1007/s11427-017-9080-y

*Corresponding author (email: shenying@bch.com.cn) 